\title{
Postoperative hemostatic efficacy of gauze soaked in tranexamic acid, fibrin sponge, and dry gauze compression following dental extractions in anticoagulated patients with cardiovascular disease: a prospective, randomized study
}

\author{
Eduardo Costa Studart Soares • Fábio Wildson Gurgel Costa • \\ Tácio Pinheiro Bezerra • Carlos Bruno Pinheiro Nogueira • \\ Paulo Goberlânio de Barros Silva • Saulo Hilton Botelho Batista • \\ Fabrício Bitu Sousa • Cristiane Sá Roriz Fonteles
}

Received: 24 January 2014 / Accepted: 8 December 2014 /Published online: 21 December 2014

(C) Springer-Verlag Berlin Heidelberg 2014

\begin{abstract}
Introduction Oral anticoagulants are widely prescribed drugs. Interruption of anticoagulant therapy prior to oral surgery has been an issue of great controversy. The purpose of this study was to evaluate the incidence of bleeding complications after dental extractions in patients on anticoagulant therapy (warfarin) in whom different local hemostatic methods were used.

Material and methods Patients using warfarin and requiring extractions of at least two teeth were screened to participate in
\end{abstract}

E. C. S. Soares

Division of Oral and Maxillofacial Surgery,

Department of Clinical Dentistry, School of Dentistry,

Federal University of Ceará, Rua Cap. Francisco Pedro S/N,

Rodolfo Teófilo, Fortaleza, CE 60430-170, Brazil

F. W. G. Costa

Division of Oral Radiology, Department of Clinical Dentistry, School of Dentistry, Federal University of Ceará, Rua Cap. Francisco

Pedro S/N, Rodolfo Teófilo, Fortaleza, CE 60430-170, Brazil

T. P. Bezerra $\cdot$ C. B. P. Nogueira $•$ S. H. B. Batista

Division of Oral and Maxillofacial Surgery Residency Program of the Walter Cantídio University Hospital from Federal University of Ceará, Rua Cap. Francisco Pedro S/N, Rodolfo Teófilo, Fortaleza,

CE 60430-170, Brazil

P. G. de Barros Silva

Division of Stomatology, Department of Clinical Dentistry, School of Dentistry, Federal University of Ceará, Rua Cap. Francisco Pedro

S/N, Rodolfo Teófilo, Fortaleza, CE 60430-170, Brazil this prospective, randomized study. Extraction sites were considered as sampling units (statistically representative sample size) and were allocated to one of the three study groups (G1-4.8 \% tranexamic acid; G2-fibrin sponge; and G3 - no local hemostatic agents).

Results Eighty-four extraction sites were obtained from patients with mitral valve prolapse $(47.4 \%)$, prosthetic cardiac valve $(23.7 \%)$, venous thromboembolism $(21.1 \%)$, and pulmonary embolism (5.2\%). International normalized ratio (INR) values ranged between 2.1 and 3.1 (mean 2.51 \pm 0.1 ).

\section{F. B. Sousa}

Division of Oral Pathology, Department of Clinical Dentistry, School of Dentistry, Federal University of Ceará, Rua Cap. Francisco Pedro S/N, Rodolfo Teófilo, Fortaleza, CE 60430-170, Brazil

\section{Sá Roriz Fonteles}

Division of Pediatric, Department of Clinical Dentistry,

School of Dentistry, Federal University of Ceará, Rua Cap. Francisco Pedro S/N, Rodolfo Teófilo, Fortaleza, CE 60430-170, Brazil

\section{F. W. G. Costa $(\bowtie)$}

Post-program in Dentistry, Faculty of Pharmacy, Dentistry and Nursing, Federal University of Ceará, Rua Cap. Francisco Pedro S/N, Rodolfo Teófilo, Fortaleza, CE 60430-170, Brazil

e-mail: fwildson@yahoo.com.br 
Postoperative bleeding was observed in four surgical sites $(p<0.001)$ and was mainly in older patients $(p=0.005)$.

Discussion The three local hemostatic protocols were similarly effective in controlling postoperative bleeding in patients undergoing anticoagulant therapy with warfarin. The majority of teeth could be extracted with minimal problems in patients with cardiovascular diseases receiving treatment with anticoagulant therapy.

Keywords Oral surgery · Dental extraction · Anticoagulants · Hemostasis

\section{Introduction}

Oral anticoagulants are widely prescribed drugs for the prevention of cerebrovascular diseases such as thromboembolism in patients with cardiac vascular prostheses, venous thrombosis, and pulmonary embolism [1-3]. At present, warfarin has been shown to be the most widely used oral anticoagulant and is indicated in several heart diseases. In recent years, interruption of anticoagulant therapy prior to oral surgery has been an issue of great controversy. Some authors warn that the discontinuation of this drug could cause an increased risk of thromboembolism, whereas anticoagulant therapy maintenance may lead to serious pre- and postsurgical bleeding [4-10].

As observed in the guidelines proposed by Perry et al.[7], the maintenance of antithrombotic therapy has been found to be valid in cases in which the international normalized ratio (INR) does not exceed the value of 4.0. However, Morimoto et al. [11], evaluating a group of patients treated with warfarin with an INR between 2.0 and 2.49, observed a postoperative bleeding percentage of $10 \%$ even after using a local hemostatic agent (oxidized cellulose) at the surgical site. In addition, a prospective study showed that patients undergoing multiple extractions and presenting preoperative INR $2.25 \pm$ 0.64 showed a statistically significant postoperative increase in the value of INR, which may influence the occurrence of postoperative bleeding events [12]. Studies have suggested uninterrupted anticoagulant therapy prior to dental extractions coupled with bleeding control through the use of local hemostatic measures as the proper conduct to be adopted in patients taking these drugs [13-16]. However, there is no established consensus to determine the most appropriate local hemostatic approach to prevent postsurgical bleeding [9, 14, 15, 17, 18]. The purposes of this study were to evaluate the efficacy of three different local hemostatic methods (gauze soaked in $4.8 \%$ tranexamic acid, fibrin sponge, and dry gauze compression) after dental extractions, in patients on anticoagulant therapy (warfarin), and to assess the incidence of bleeding complications among these individuals. The present study tested the hypothesis that there is no difference in the prevention of postsurgical bleeding among anticoagulated patients with cardiovascular disease subjected to gauze soaked in $4.8 \%$ tranexamic acid, fibrin sponge, or dry gauze compression to assure local hemostasis.

\section{Patients and methods}

Study design and sample selection

This study presented a prospective, unicenter, randomized, design and was approved by the Ethics Committee of the Ceará Academy of Dentistry (protocol no. 00/86), in Fortaleza (Brazil). Patients from both genders, with a minimum of 18 years age, examined at the Cardiology Department of Walter Cantídio University Hospital (Federal University of Ceará, Brazil) between January and December 2009, using warfarin, and requiring extractions of at least two teeth, were screened to participate in this study. Individuals who (1) used associated anticoagulating medications (other than warfarin); (2) were smokers, pregnant, or lactating; and (3) reported preexisting blood dyscrasias were excluded from the study. Patients who did not return for reassessment were removed from the study (Fig. 1).

The following variables were recorded for each subject prior to surgical intervention: gender, age, medical condition, INR value, presence of periodontal disease and/or caries, and number/type of teeth requiring extraction. Extraction sites were considered as sampling units and, according to the local hemostatic procedure to be performed, were randomly allocated into one of the three study groups by using a computergenerated code: (G1) gauze pad soaked in $4.8 \%$ tranexamic acid (Transamin ${ }^{\circledR}$, Nikkho, Rio de Janeiro, Brazil) was applied to the surgical alveolus for 8 min under biting pressure; (G2) fibrin sponge (Hemospon ${ }^{\circledR}$, Technew, Rio de Janeiro, Brazil) was packed into the surgical alveolus, and the patient was asked to bite down on dry gauze for $8 \mathrm{~min}$ for compression; and (G3) dry gauze compression was performed under biting pressure on the surgical alveolus for $8 \mathrm{~min}$ without the use of local hemostatic agents. Thus, one patient could be subjected to different local hemostatic methods depending on the table created for randomization, respecting a 30-day interval between procedures. Only one tooth was extracted per appointment. Hemostatic procedures were performed immediately after dental extraction and prior to suture placement of the surgical wounds.

\section{Sample size calculation}

Sample size was calculated based on the study by Al-Belasy et al. [20]. The null hypothesis of the present study considered that there is no statistical difference in the occurrence of 
postoperative bleeding among anticoagulated patients subjected to the use of local hemostatic agents (experimental groups) versus dry gauze compression (control group). Hence, in order to attain a statistical power of at least $80 \%$ within a confidence interval of $95 \%$, and a type I error of 0.05 (chi-square test without any correction), at least 19 surgical procedures would be needed per group. The present study was conducted with a final sample size of 28 extraction sites per group and equal distribution $(p=1.000)$ (Fig. 1). Data analysis through chisquare test without any correction showed a probability of postsurgical bleeding within the range of 3.6-7.1\% (mean of $5.3 \%$ ) in the experimental groups that used tranexamic acid and fibrin sponge, versus $3.6 \%$ for the group that used gauze compression alone (control). Thus, it could be assumed that the presently described results showed a minimum statistical power of $91.1 \%$ and a maximum of $95 \%$, being statistically representative and presenting external validity $(95 \% \mathrm{CI}$, type I error of 0.05).

\section{Surgical overview}

All patients were submitted to a standardized surgical technique, performed in an outpatient setting, under local anesthesia, in

Fig. 1 Flow chart of patients recruited for study groups. Asterisk indicates the G1 group (gauze soaked in $4.8 \%$ tranexamic acid), two asterisks indicate the G2 group (fibrin sponge), and three asterisks indicate the G3 group (compression of the postextraction site with dry gauze) accordance with strict biosafety control, and without interruption of anticoagulation therapy. On the day of surgery, blood was collected preoperatively to obtain INR values. All dental extractions were performed by the same surgical team, in which the operator was an oral and maxillofacial surgeon with 5-year experience in dentoalveolar surgery.

The teeth were extracted with minimal trauma, and the surgical site was occluded with suture in " $\mathrm{X}$ " fashion (silk 4.0) irrespective of the local hemostatic method used. In order to control for the extent of surgical trauma, surgical sites subjected to procedures requiring mucoperiosteal flap for dental extractions or that lasted longer than 30 min were not included in the study sample. In the presence of postoperative bleeding, the protocol previously used in that specific extraction site was repeated. When bleeding persisted, the surgical site was inspected to identify any remaining bone and/or soft tissue debris; curettage was performed, followed by intrasocket introduction of a fibrin sponge, suture in " $\mathrm{X}$ " fashion, and compression using gauze soaked in $4.8 \%$ tranexamic acid for $8 \mathrm{~min}$. If after this procedure, residual bleeding was perceived, the patient would be conducted to the university hospital for evaluation by a previously designated team of professionals. The suture was removed 7 days after surgery.

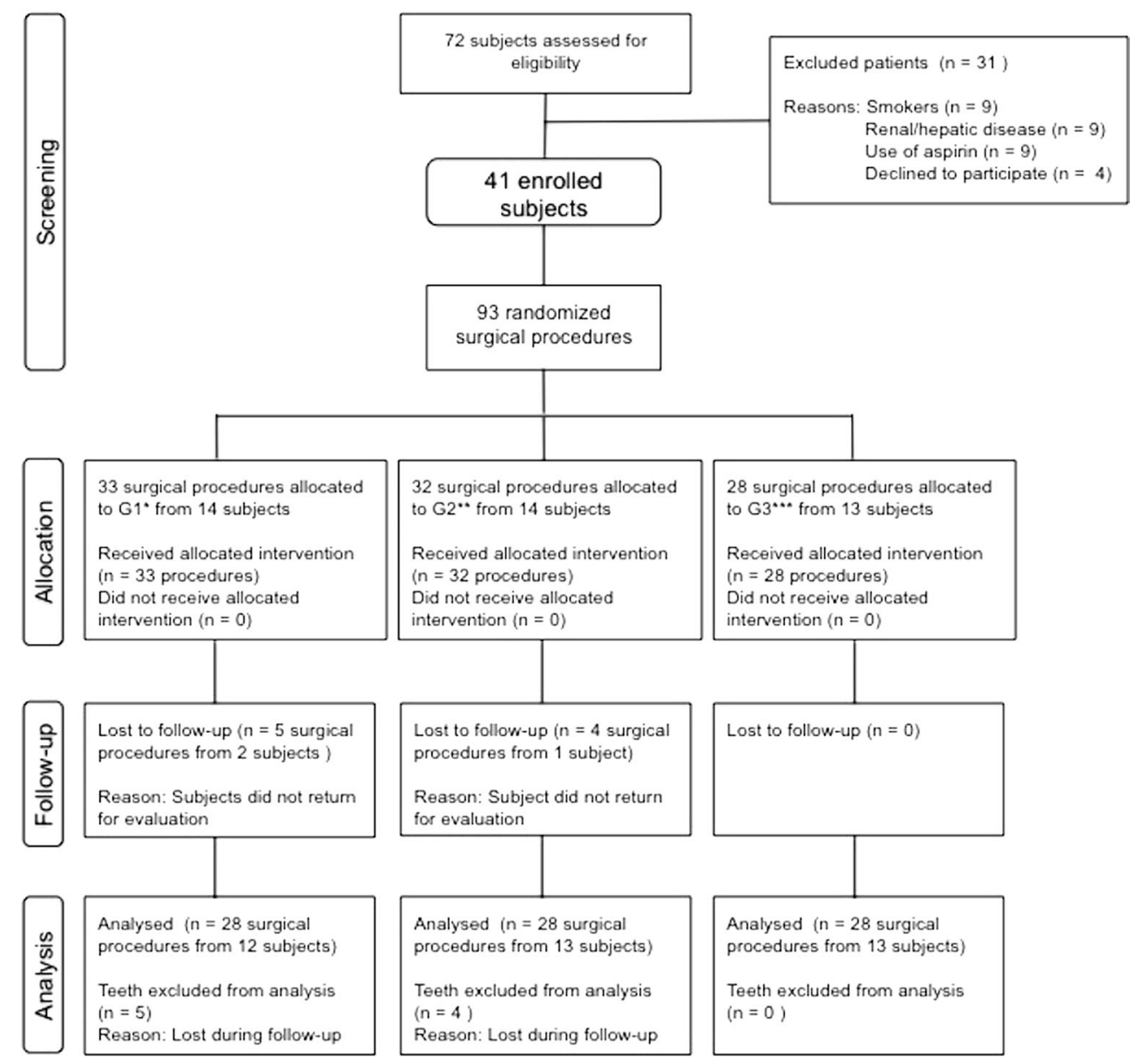


Patients with risk for infective endocarditis were instructed to take prophylactic amoxicillin $2 \mathrm{~g}$ or, if allergic, clarithromycin $500 \mathrm{mg}, 1 \mathrm{~h}$ before surgery, according to the latest guidelines from the American Heart Association [19]. Postoperatively, in all cases, acetaminophen $(500 \mathrm{mg}$, one tablet every $6 \mathrm{~h}$ over 2 days) was prescribed to provide analgesia, and patients were instructed not to ingest aspirin or other anti-inflammatory drugs for at least 10 days [20]. Postoperative recommendations were read and explained to patients, especially to observe a liquid and cold diet and not use mouthwash during the first $24 \mathrm{~h}$ after surgery [21]. In addition, patients were advised to call if bleeding persisted even after biting down on dry gauze for up to $20 \mathrm{~min}$ for compression [20, 22], or if they experienced any other complications such as pain and fever.

\section{Outcome measure}

The primary outcome measure of the study was the prevalence of postoperative bleeding. The difference in the occurrence of bleeding complications between the study groups consisted on the secondary outcome measure. Bleeding complication was evaluated by contacting the patients by telephone 12 and $24 \mathrm{~h}$ after surgery [13]. In addition, each patient was instructed to report any unusual bleeding until the seventh postoperative day. Individuals returned after 1 week for suture removal and wound inspection. Postoperative hemorrhage was defined as bleeding on the extraction site that could not be controlled by gauze compression during $20 \mathrm{~min}$ and/ or hemostasis requiring medical intervention [23]. The patients were told to contact the oral surgeon when hemostasis took longer than $20 \mathrm{~min}$ to be obtained [22]. The investigator who contacted the study participants for the purpose of evaluating bleeding complications was blinded to the hemostatic protocol allocation throughout the study period.

\section{Statistical analysis}

Parametric data (INR and age) were expressed as mean \pm standard deviation (SD) and analyzed with Student's $t$ test or ANOVA followed by Tukey post hoc tests. Categorical variables (gender, age range, upper/lower or anterior/posterior teeth, reason for dental extraction, study group, and presence/absence of bleeding) were expressed as absolute frequencies and percentages. Association between these variables was assessed by Fisher's exact or chi-square tests. Confidence intervals were calculated for sample characterization. All statistical analysis was conducted using Statistical Package for the Social Sciences software, version 15.0 for Windows (SPSS, Chicago, IL, USA). Results were considered significant when $p<0.05$.

\section{Results}

Clinicodemographic profile

A total of 72 patients were assessed for eligibility for this study. Of these, 31 subjects were excluded (smokers, $n=9$; renal impairment, $n=6$; liver impairment, $n=3$; did not agree to participate, $n=4$; aspirin being concomitantly used, $n=9$ ), and 3 patients were removed from the study because they did not return for postoperative bleeding reassessment, rendering a total of 38 patients and a final sample size of 84 extraction sites (28 per group) (Fig. 1). Among the indications for anticoagulant therapy, the presence of mitral valve prolapse was the most prevalent $(47.4 \%, n=18)$, followed by the presence of prosthetic cardiac valve $(23.7 \%, n=9)$, venous thromboembolism $(21.1 \%, n=8)$, and pulmonary embolism $(5.2 \%, n=3)$.

Table 1 General characterization of the study sample $(n=84$ surgical sites)

\begin{tabular}{|c|c|c|c|}
\hline Variables & Sample (\%) & $95 \% \mathrm{CI}$ & $p$ value* \\
\hline \multicolumn{4}{|l|}{ Gender } \\
\hline Male & $56(66.7 \%)$ & $55.5-75.1$ & \multirow[t]{2}{*}{0.028} \\
\hline Female & $28(33.3 \%)$ & $23.4-44.4$ & \\
\hline \multicolumn{4}{|l|}{ Age (years) } \\
\hline Mean \pm SD & $51.1 \pm 3.0$ & $50.4-51.7$ & \\
\hline Median (min-max) & $52(44-56)$ & - & \\
\hline \multicolumn{4}{|l|}{ Age range (years) } \\
\hline$<50$ & $22(26.2 \%)$ & $17.2-36.9$ & \multirow[t]{2}{*}{0.009} \\
\hline$\geq 50$ & $52(73.8 \%)$ & $50.6-72.3$ & \\
\hline \multicolumn{4}{|l|}{ INR } \\
\hline Mean \pm SD & $2.5 \pm 0.1$ & $2.5-2.6$ & \\
\hline Median (min-max) & $2.5(2.1-3.1)$ & - & \\
\hline \multicolumn{4}{|l|}{ Surgical sites } \\
\hline Maxilla & $44(52.4 \%)$ & $41.2-63.4$ & \multirow[t]{2}{*}{0.757} \\
\hline Mandible & $40(47.6 \%)$ & $36.6-58.8$ & \\
\hline \multicolumn{4}{|l|}{ Type of teeth } \\
\hline Anterior & $18(21.4 \%)$ & $13.2-31.7$ & \multirow[t]{2}{*}{$<0.001$} \\
\hline Posterior & $66(78.6 \%)$ & $68.2-86.7$ & \\
\hline \multicolumn{4}{|l|}{ Reason for extraction } \\
\hline Dental caries & $55(65.5 \%)$ & $54.3-75.5$ & \multirow[t]{2}{*}{0.042} \\
\hline Periodontal disease & $29(34.5 \%)$ & $24.4-45.7$ & \\
\hline \multicolumn{4}{|l|}{ Study groups } \\
\hline Tranexamic acid (G1) & $28(33.3 \%)$ & $23.4-44.5$ & \multirow[t]{3}{*}{1.000} \\
\hline Fibrin sponge (G2) & $28(33.3 \%)$ & $23.4-44.5$ & \\
\hline Gauze (G3) & $28(33.3 \%)$ & $23.4-44.5$ & \\
\hline \multicolumn{4}{|l|}{ Postoperative bleeding } \\
\hline Present & $4(4.8 \%)$ & $1.3-11.7$ & \multirow[t]{2}{*}{$<0.001$} \\
\hline Absent & $80(95.2 \%)$ & $88.2-98.7$ & \\
\hline
\end{tabular}

$95 \%$ CI confidence interval in $95 \%$ of the sample, $S D$ standard deviation, min minimum, max maximum

$*_{p}<0.05$ (chi-square test) 
Of the 38 patients available for study, 22 (57.9\%) were men and $16(42.1 \%)$ were women. There was no statistically significant difference related to gender $(p=0.490)$. Fifty-six extraction sites $(66.7 \%)$ were pertained to male patents, versus $28(33.3 \%)$ extraction sites from females $(p=0.028)$. The age ranged from 44 to 56 years. The mean age (years) of the studied sample was $51.1 \pm 3.0$, and a significant majority $(73.8 \%)$ of these patients were $\geq 50$ years of age $(p=0.009)$. A mean INR of $2.5 \pm 0.1$ was observed, with minimum and maximum values of 2.1 and 3.1, respectively. The number of extraction sites did not differ between the maxilla $(52.4 \%)$ and mandible (47.6\%) $(p=0.757)$. However, a greater number of extraction sites were observed in the posterior areas $(78.6 \%)$ of the maxilla and mandible, as opposed to the anterior regions $(21.4 \%)(p<0.001)$. Dental caries was the reason for dental extraction in the majority of cases $(n=55$; $65.5 \%)$, followed by periodontitis $(n=29 ; 34.5 \%)(p=0.042)$. A total of four bleeding episodes were reported throughout the study $(4.8 \%)$. This value was significantly lower when compared to the absence of postoperative hemorrhage $(95.2 \%)$ $(p<0.001)$ (Table 1).

The mean INR $(p=0.898)$ and age $(p=0.983)$ did not differ between groups. In addition, mean age did not differ between genders $(p=0.807)$, anterior/posterior position of the extraction sites $(p=0.428)$, reasons for dental extraction $(p=0.195)$, and the presence/absence of bleeding episodes $(p=0.769)$. When all groups were considered, there was a higher prevalence of extraction sites in the maxilla (52.4\%) when compared to the mandible $(47.6 \%)(p=0.007)$. However, when groups were individually analyzed in regard to location of extraction sites, a greater number of sites were observed in the maxilla among those treated with tranexamic acid $(p<0.05)$, while more mandibular extraction sites were encountered among controls $(p<0.05)$ (Table 2$)$.

The presence of bleeding did not associate with INR values ( $p=0.897)$, gender $(p=1.000)$, location of the extraction sites (maxilla/mandible: $p=1.000$; anterior/posterior positions: $p=$ $0.573)$, reason for dental extractions $(p=0.606)$, or hemostatic method ( $p=0.769)$. Nevertheless, patients with postoperative bleeding presented a mean age of $51.3 \pm 2.8$ years and were significantly older $(p=0.005)$ than those who did not present bleeding episodes (47.0 \pm 4.0 years) (Table 3$)$. No significant differences between mean ages were observed between genders $(p=0.153)$, location of the extraction sites (maxilla/mandible: $p=0.487$, anterior/posterior: $p=0.147)$, and reasons for dental extractions $(p=0.424)$ (Table 4$)$.

Provided that depending on the number of extraction sites, a patient could have received different treatments, statistics was adjusted to only consider the independency of target events (postoperative bleeding) when a given patient was subjected to a single type of treatment. In the instances in which patients presented two extraction sites and received two different treatments or three or + extraction sites and received three different treatments, these individuals were considered their own controls. Hence, all patients were grouped according to the number of received treatments. Study participants were grouped as follows (Table 5): patients subjected to single treatment (those with a single extraction site), patients subjected to two different treatments (those with two extraction sites), and patients subjected to at least three different

Table 2 Characterization of the experimental groups according to the studied variables ( $n=84$ surgical sites)

\begin{tabular}{|c|c|c|c|c|}
\hline Variables & Tranexamic acid (G1) & Fibrin sponge (G2) & Gauze (G3) & $p$ value** \\
\hline $\mathrm{INR}($ mean $\pm \mathrm{SD})$ & $2.52 \pm 0.16$ & $2.51 \pm 0.16$ & $2.51 \pm 0.13$ & $0.898 \dagger$ \\
\hline Age in years $($ mean \pm SD) & $51.0 \pm 2.9$ & $51.1 \pm 3.3$ & $51.1 \pm 2.8$ & $0.983 \dagger$ \\
\hline \multicolumn{5}{|l|}{ Gender } \\
\hline $\begin{array}{l}\text { Male } \\
\text { Female }\end{array}$ & $\begin{array}{l}18(32.1 \%) \\
10(35.7 \%)\end{array}$ & $\begin{array}{l}20(35.7 \%) \\
8(28.6 \%)\end{array}$ & $\begin{array}{l}18(32.1 \%) \\
10(35.7 \%)\end{array}$ & 0.807 \\
\hline \multicolumn{5}{|l|}{ Surgical site } \\
\hline $\begin{array}{l}\text { Maxilla } \\
\text { Mandible }\end{array}$ & $\begin{array}{l}19(43.2 \%)^{*} \\
9(22.5 \%)\end{array}$ & $\begin{array}{l}17(38.6 \%) \\
11(27.5 \%)\end{array}$ & $\begin{array}{l}8(18.2 \%) \\
20(50.0 \%)^{*}\end{array}$ & 0.007 \\
\hline \multicolumn{5}{|l|}{ Type of teeth } \\
\hline $\begin{array}{l}\text { Anterior } \\
\text { Posterior }\end{array}$ & $\begin{array}{l}8(44.4 \%) \\
20(30.3 \%)\end{array}$ & $\begin{array}{l}4(22.2 \%) \\
24(36.4 \%)\end{array}$ & $\begin{array}{l}6(33.3 \%) \\
22(33.3 \%)\end{array}$ & 0.428 \\
\hline \multicolumn{5}{|l|}{ Reason for extraction } \\
\hline $\begin{array}{l}\text { Dental caries } \\
\text { Periodontal disease }\end{array}$ & $\begin{array}{l}22(40.0 \%) \\
6(20.7 \%)\end{array}$ & $\begin{array}{l}17(30.9 \%) \\
11(37.9 \%)\end{array}$ & $\begin{array}{l}16(29.1 \%) \\
12(41.4 \%)\end{array}$ & 0.195 \\
\hline \multicolumn{5}{|l|}{ Surgical site } \\
\hline $\begin{array}{l}\text { Maxilla } \\
\text { Mandible }\end{array}$ & $\begin{array}{l}27(33.8 \%) \\
1(25.0 \%)\end{array}$ & $\begin{array}{l}26(32.5 \%) \\
2(50.0 \%)\end{array}$ & $\begin{array}{l}27(33.8 \%) \\
1(25.0 \%)\end{array}$ & 0.769 \\
\hline
\end{tabular}

${ }^{*} p<0.05$ (chi-square or Fisher's exact test with Bonferroni correction); ${ }^{* *} p<0.05$ (chi-square test); $\dagger p<0.05$ (ANOVA/Tukey tests) 
treatments (those with three or more extraction sites). Among the patients submitted to a unique local hemostatic procedure, there was no statistically significant evidence $(p=0.319)$ of postoperative bleeding occurrence in the surgical sites treated with tranexamic acid $(n=0,0.0 \%)$, fibrin sponge $(n=1$, $16.7 \%)$, or gauze $(n=0,0.0 \%)$. Of the total of patients that received only two different treatments (tranexamic acid and fibrin sponge, $n=2$; tranexamic acid and gauze, $n=2$; fibrin sponge and gauze, $n=2)$, there was no statistically significant difference regarding bleeding events $(p=1.00)$. Among the patients submitted to the three studied groups in different moments, only one patient presented postoperative bleeding in all surgical sites (tranexamic acid, $n=1$; fibrin sponge, $n=1$; gauze, $n=1)$, and there was no statistically significant difference among studied groups $(p=0.999)$.

\section{Discussion}

This survey was a randomized clinical study with anticoagulated patients from a cardiology service where discontinuation of this therapy does not configure as a routine practice. In this study, we decided during the conception study phase not to perform an intention-to-treat (ITT) analysis, due to the following reasons: (1) The association of missing data from subjects who did not return to evaluation with data from

Table 3 Distribution of INR, age, gender, surgical site, tooth type, reason for dental extraction, and study groups according to the presence/absence of postoperative bleeding ( $n=84$ surgical sites)

\begin{tabular}{llll}
\hline Variables & \multicolumn{2}{l}{ Postoperative bleeding } & \multirow{2}{*}{$p$ value* } \\
\cline { 2 - 3 } & Presence & Absence & \\
\hline INR (mean \pm SD) & $2.5 \pm 0.1$ & $2.5 \pm 0.1$ & $0.897 \dagger$ \\
Age (mean \pm SD) & $51.3 \pm 2.8 \dagger$ & $47.0 \pm 4.0$ & $0.005 \dagger$ \\
Gender & & & \\
$\quad$ Male & $3(5.4 \%)$ & $53(94.6 \%)$ & 1.000 \\
$\quad$ Female & $1(3.6 \%)$ & $27(96.4 \%)$ & \\
Surgical site & & & \\
$\quad$ Maxilla & $2(4.5 \%)$ & $48(95.5 \%)$ & 1.000 \\
$\quad$ Mandible & $2(5.0 \%)$ & $38(95.0 \%)$ & \\
Type of teeth & & & \\
$\quad$ Anterior & $0(0.0 \%)$ & $18(100.0 \%)$ & 0.573 \\
Posterior & $4(6.1 \%)$ & $62(93.9 \%)$ & \\
Reason for extraction & & & \\
$\quad \begin{array}{l}\text { Dental caries } \\
\text { Periodontal disease }\end{array}$ & $2(3.6 \%)$ & $53(96.4 \%)$ & 0.606 \\
Study group & $2(6.9 \%)$ & $27(93.1 \%)$ & \\
$\quad$ Tranexamic acid (G1) & $1(3.6 \%)$ & $27(96.4 \%)$ & 0.769 \\
Fibrin sponge (G2) & $2(7.1 \%)$ & $26(92.9 \%)$ & \\
Gauze (G3) & $1(3.6 \%)$ & $27(96.4 \%)$ & \\
\hline
\end{tabular}

$*_{p}<0.05$ (Fisher's exact test); $\dagger p<0.05$ ( $t$ test)
Table 4 Mean age distribution (years) according to gender, surgical site, type of teeth, and reason for dental extraction ( $n=84$ surgical sites)

\begin{tabular}{lcc}
\hline Variables & Mean \pm SD & $p$ value* \\
\hline Gender & & \\
$\quad$ Male & $50.1 \pm 3.4$ & 0.153 \\
$\quad$ Female & $51.7 \pm 1.8$ & \\
Surgical site & & 0.487 \\
$\quad$ Maxilla & $50.9 \pm 3.2$ & \\
$\quad$ Mandible & $51.3 \pm 2.8$ & \\
Type of teeth & & \\
$\quad$ Anterior & $52.0 \pm 2.2$ & \\
$\quad$ Posterior & $50.8 \pm 3.2$ & \\
Reason for extraction & & \\
$\quad$ Dental caries & & \\
Periodontal disease & $50.9 \pm 3.2$ & \\
\hline$* p<0.05$ ( $t$ test) & $51.4 \pm 2.7$ &
\end{tabular}

participants that complete the follow-up period could introduce heterogeneity to the final analysis, (2) end-point data from compliant subjects would differ significantly among participants who did not return for follow-up visits, and (3) analysis of missing data coupled with the data collected from subjects assigned to receive different interventions could produce some misinterpretation of the results.

The surgical approach in dental patients undergoing treatment with warfarin may be associated with complications according to whether or not the anticoagulated therapy is maintained. This decision leads to either increased bleeding risk (maintenance) or the establishment of thromboembolic events (suspension) [4, 6, 10, 24-31]. Presently, surgical

Table 5 Postoperative bleeding events per individual subjected to a single or different local hemostatic procedure at surgical sites

\begin{tabular}{|c|c|c|c|c|}
\hline \multirow{2}{*}{$\begin{array}{l}\text { Postoperative } \\
\text { bleeding }\end{array}$} & \multicolumn{3}{|l|}{ Groups } & \multirow[t]{2}{*}{$p$ value* } \\
\hline & $\begin{array}{l}\text { Tranexamic } \\
\text { acid }\end{array}$ & $\begin{array}{l}\text { Fibrin } \\
\text { sponge }\end{array}$ & Gauze & \\
\hline \multicolumn{5}{|c|}{ Patients subjected to 1 single treatment ${ }^{\mathrm{a}}$} \\
\hline $\begin{array}{l}\text { Absence } \\
\text { Presence }\end{array}$ & $\begin{array}{l}7(100.0 \%) \\
0(0.0 \%)\end{array}$ & $\begin{array}{l}5(83.3 \%) \\
1(16.7 \%)\end{array}$ & $\begin{array}{l}6(100.0 \%) \\
0(0.0 \%)\end{array}$ & 0.319 \\
\hline \multicolumn{5}{|c|}{ Patients subjected to 2 different treatments ${ }^{\mathrm{b}}$} \\
\hline $\begin{array}{l}\text { Absence } \\
\text { Presence }\end{array}$ & $\begin{array}{l}4(100.0 \%) \\
0(0.0 \%)\end{array}$ & $\begin{array}{l}4(100.0 \%) \\
0(0.0 \%)\end{array}$ & $\begin{array}{l}4(100.0 \%) \\
0(0.0 \%)\end{array}$ & 1.000 \\
\hline \multicolumn{5}{|c|}{ Patients subjected to at least 3 different treatments ${ }^{\mathrm{c}}$} \\
\hline $\begin{array}{l}\text { Absence } \\
\text { Presence }\end{array}$ & $\begin{array}{c}16(94.1 \%) \\
1(5.9 \%)\end{array}$ & $\begin{array}{c}17(94.4 \%) \\
1(5.6 \%)\end{array}$ & $\begin{array}{c}17(94.4 \%) \\
1(5.6 \%)\end{array}$ & 0.999 \\
\hline
\end{tabular}


procedures were performed without discontinuation of warfarin, and no severe cases of bleeding were experienced.

In recent years, many studies have discussed the effectiveness of different local hemostatic measures for controlling postoperative bleeding without the need for altering the anticoagulant therapy $[8,13-16,25,32,33]$. In these cases, there are surveys that indicate the use of tranexamic acid as mouthwash $[4,9,22,34]$ and the use of absorbable sponges as effective measures in preventing such events $[35,36]$. In the present study, the presence of bleeding was compared in patients who underwent dental extractions using $4.8 \%$ tranexamic acid, fibrin sponge, and dry sponge in the surgical site as local hemostatic measures. We sought to identify possible factors that could interfere with hemostatic response after tooth extraction such as (1) influence of the type of tooth extracted, (2) reason for tooth extraction, (3) influence of the INR value on the day of the procedure, and (4) effectiveness of each method employed. When considering the types of teeth among the groups, we observed a larger number of patients who underwent extraction of multiradicular teeth, specifically maxillary molars in G1, maxillary premolars in G2, and mandibular molars in G3. According to Carter and Goss [14], although differences in the extraction site do not associate with increased bleeding, the number of extracted teeth seems to interfere with the amount of bleeding in cases of multiple extractions. The present study is in agreement with these results, but these findings cannot be extrapolated to this study because we have outlined only one extraction procedure per day with intervals of 30 days until the next intervention.

By analyzing the reason for tooth extraction and the occurrence of postoperative bleeding, advanced periodontal disease was observed as the main factor related to bleeding. This fact is supported by authors such as Blinder et al. [13] and Carter and Goss [14] who observed a higher rate of complications related to bleeding after tooth extraction for periodontal reasons. A higher degree of inflammation surrounding the extraction sites and larger amounts of granulation tissue [8] may explain this association. The INR is an index derived from laboratory prothrombin time, which has been described since 1983 , and it has been universally accepted as a complementary test for monitoring the effect of anticoagulant medication [37]. In the present study, the INR ranged between 2.1 and 3.1, and it was found that there was no statistical difference in the mean value of INR (mean of about 2.5) between groups. In surveys in which the INR ranged between 2.0 and 4.0, the authors also found no statistically significant differences related to bleeding after tooth extraction $[15,38]$. In the present study, patients subjected to maxillary molar extractions had an INR value of 2.5 on the day of the procedure, while those in the maxillary premolar group had a value of 2.4 , and these values did not differ statistically. The absence of the influence of the INR was also ratified by Zanon [39] in which groups with three different therapeutic intervals of INR $(1.8-2.0,2.0$
3.0, and 3.0-4.0) were studied, and no differences were noted in the occurrence of bleeding when comparing the INR levels. Brooks [40] reported two cases (third molar extraction in a 64year-old male, INR 2.5/multiple extractions in an 84-year-old female, INR 1.2) of severe hemorrhage in patients under warfarin therapy, who received local hemostatic treatment at the surgical site (gelatin sponge). The authors concluded that an increase in age might interfere in the process of coagulation, in spite of an approximately normal INR value. In the present study, the risk of bleeding was directly associated with age, regardless of the hemostatic measure adopted, supporting the possibility of an age-factor influence over hemostasis.

Presently, sutures associated with gauze soaked in $4.8 \%$ tranexamic acid, fibrin sponge, or mechanical compression with dry gauze was efficient in controlling postoperative bleeding. The effectiveness of biting down on dry gauze without tranexamic acid in the prevention of bleeding events was considered the most interesting result. Dry gauze compression seems to be efficient in bleeding control, and in oral surgeries, the major vessels are not injured; thus, the control of hemostasis is mainly related to the primary phase of coagulation, i.e., more dependent on platelet function, which is not directly influenced by the use of warfarin [24-26]. It is believed that the grave importance of the pathophysiological role of local fibrinolysis in the development of postsurgical bleeding shared by patients with impaired fibrin formation is also observed by those on chronic warfarin therapy [40].

\section{Conclusion}

Within the scope of this clinical trial, it may be concluded that in the patients whose anticoagulant therapy was not interrupted, the three local hemostatic methods showed effectiveness in preventing postoperative bleeding. In addition, postoperative bleeding was not dependent on the INR value. Compression with dry gauze bandage without the addition of local hemostatic agents was as effective as other local hemostatic measures in anticoagulated patients.

Conflict of interest The authors declare that there is no conflict of interest.

\section{References}

1. Jiménez Y, Poveda R, Gavaldá C, Margaix M, Sarrión G (2008) An update on the management of anticoagulated patients programmed for dental extractions and surgery. Med Oral Patol Oral Cir Bucal 13(3):176-179

2. Nutescu E, Chuatrisorn I, Hellenbart E (2011) Drug and dietary interactions of warfarin and novel oral anticoagulants: an update. J Thromb Thrombolysis 31(3):326-343 
3. Thethi I, Fareed J (2011) Newer oral anticoagulants: a promising future. Clin Appl Thromb Hemost 17:235

4. Souto J, Oliver A, Zuazu-jausoro I, Vives A, Fontcuberta J (1996) Oral surgery in anticoagulated patients without reducing the dose of oral anticoagulant: a prospective randomized study. J Oral Maxillofac Surg 54(1):27-32

5. Bacci C, Maglione M, Favero L, Perini A, Di Lenarda R, Berengo M et al (2010) Management of dental extraction in patients undergoing anticoagulant treatment. Results from a large, multicentre, prospective, case-control study. Thromb Haemost 104(5):972-975

6. Bacci C, Berengo M, Favero L, Zanon E (2011) Safety of dental implant surgery in patients undergoing anticoagulation therapy: a prospective case-control study. Clin Oral Implants Res 22(2):151156

7. Perry DJ, Noakes TJ, Helliwell PS; British Dental Society (2007) Guidelines for the management of patients on oral anticoagulants requiring dental surgery. Br Dent J 203(7):389-393

8. Blinder D, Manor Y, Martinowitz U, Taicher S (2001) Dental extractions in patients maintained on oral anticoagulant therapy: comparison of INR value with occurrence of postoperative bleeding. Int $\mathbf{J}$ Oral Maxillofac Surg 30(6):518-521

9. Evans IL, Sayers MS, Gibbons AJ, Price G, Snooks H, Sugar AW (2002) Can warfarin be continued during dental extraction? Results of a randomized controlled trial. Br J Oral Maxillofac Surg 40(3): 248-252

10. van Diermen DE, Aartman IH, Baart JA, Hoogstraten J, van der Waal I (2009) Dental management of patients using antithrombotic drugs: critical appraisal of existing guidelines. Oral Surg Oral Med Oral Pathol Oral Radiol Endod 107(5):616-624

11. Morimoto Y, Niwa H, Minematsu K (2008) Hemostatic management of tooth extractions in patients on oral antithrombotic therapy. J Oral Maxillofac Surg 66(1):51-57

12. Malden NJ, Santini A, Mather CI, Gardner A (2007) Minor oral surgery and interference with anticoagulation in patients taking warfarin: a retrospective study. Br J Oral Maxillofac Surg 45(8):645-647

13. Blinder D, Manor Y, Martinowitz TS, Hashomer T (1999) Dental extractions in patients maintained on continued oral anticoagulant: comparison of local hemostatic modalities. Oral Surg Oral Med Oral Pathol Oral Radiol Endod 88(2):137-140

14. Carter G, Goss A (2003) Tranexamic acid mouthwash - a prospective randomized study of a 2-day regimen vs 5-day regimen to prevent postoperative bleeding in anticoagulated patients requiring dental extractions. Int J Oral Maxillofac Surg 32(5):504-507

15. Carter G, Goss A, Lloyd J, Lloyd J, Tocchetti R (2003) Tranexamic acid mouthwash versus autologous fibrin glue in patients taking warfarin undergoing dental extractions: a randomized prospective clinical study. J Oral Maxillofac Surg 61(12):1432-1435

16. Kamien M (2006) Remove the tooth, but don't stop the warfarin. Aust Fam Physician 35(4):233-235

17. Beirne OR (2005) Evidence to continue oral anticoagulant therapy for ambulatory oral surgery. J Oral Maxillofac Surg 63(4):540-545

18. Ramli R, Abdul Rahman R (2005) Minor oral surgery in anticoagulated patients: local measures alone are sufficient for haemostasis. Singap Dent J 27(1):13-16

19. Wilson W, Taubert KA, Gewitz M, Lockhart PB, Baddour LM, Levison M et al (2007) Prevention of infective endocarditis: guidelines from the American heart association: a guideline from the American heart association rheumatic fever, endocarditis and Kawasaki disease committee, council on cardiovascular disease in the young, and the council on clinical cardiology, council on cardiovascular surgery and anesthesia, and the quality of care and outcomes research interdisciplinary working group. J Am Dent Assoc 138(6): $739-760$
20. Al-Belasy FA, Amer MZ (2003) Hemostatic effect of n-butyl-2cyanoacrylate (histoacryl) glue in warfarin-treated patients undergoing oral surgery. J Oral Maxillofac Surg 61(12):1405-1409

21. Bakathir AA (2009) Minor oral surgery procedures in patients taking warfarin: a 5-year retrospective study at Sultan Qaboos university hospital, sultanate of Oman. Sultan Qaboos Univ Med J 9(3):279286

22. Ramstrom G, Sindet-Pedersen S, Hall G, Blombäck M, Alander U (1993) Prevention of postsurgical bleeding in oral surgery using tranexamic acid without dose modification of oral anticoagulants. J Oral Maxillofac Surg 51(11):1211-1216

23. Behrman S, Wright I (1961) Dental surgery during continuous anticoagulation therapy. J Am Dent Assoc 62:172

24. Wahl M (1998) Dental surgery in anticoagulated patients. Arch Intern Med 158(15):1610-1616

25. Wahl M (2000) Myths of dental surgery in patients receiving anticoagulant therapy. J Am Dent Assoc 131(1):77-88

26. Ziffer AM, Scopp IW, Beck J, Baum J, Berger AR (1957) Profound bleeding after dental extraction during dicumarol therapy. $\mathrm{N}$ Engl $\mathrm{J}$ Med 256(8):351-353

27. Weibert RT (1992) Oral anticoagulant therapy in patients undergoing dental surgery. Clin Pharm 11(10):857-864

28. Poller L, Thomson J (1964) Evidence for "rebound" hypercoagulability after stopping anticoagulants. Lancet 2(7350):62-64

29. Duvoisin GE, Brandenburg RO, Mcgoon DC (1967) Factors affecting thromboembolism associated with prosthetic heart valves. Circulation 35(4):70-76

30. Akbarian M, Austen WG, Yurchak PM, Scannell JG (1968) Thromboembolic complications of prosthetic cardiac valves. Circulation 37(5):826-831

31. Scully C, Wolff A (2002) Oral surgery in patients on anticoagulant therapy. Oral Surg Oral Med Oral Pathol Oral Radiol Endod 94(1): $57-64$

32. Cannon PD, Dharmar VT (2003) Minor oral surgical procedures in patients on oral anticoagulants - a controlled study. Aust Dent J 48(2): $115-118$

33. Gaspar R, Brenner B, Ardekian L, Peled M, Laufer D (1997) Use of tranexamic acid mouthwash to prevent postoperative bleeding in oral surgery patients on oral anticoagulant medication. Quintessence Int 28(6):375-359

34. Blinder D, Ardekian L, Peleg M, Peleg M, Taicher S (1996) Oral surgical procedures in patients on anticoagulant therapy. Harefuah 130(10):681-683

35. Bodner L, Weinstein JM, Baumgarten AK (1998) Efficacy of fibrin sealant in patients on various levels of oral anticoagulant undergoing oral surgery. Oral Surg Oral Med Oral Pathol Oral Radiol Endod 86(4):421-424

36. Poller L (1983) Standardization of oral anticoagulant treatment. $\mathrm{Br}$ Med J (Clin Res Med) 287(6402):1379

37. Webster K, Wilde J (2000) Management of anticoagulation in patients with prosthetic heart valves undergoing oral and maxillofacial operations. Br J Oral Maxillofac Surg 38(2):124-126

38. Zanon E, Martinelli F, Bacci C, Cordioli G, Girolami A (2003) Safety of dental extraction among consecutive patients on oral anticoagulant treatment managed using a specific dental management protocol. Blood Coagul Fibrinolysis 14(1):27-30

39. Brooks AS (2011) Delayed complications of tooth extraction in patients taking warfarin, antibiotics, and other medications. J Oral Maxillofac Surg 69(9):977-979

40. Majeurs P, Dalcette B, Hermans M, Pourtois M, Capel P (1996) Variations in fibrinolytic activity of human whole saliva. Eur J Oral Sci 104(4):341-345 